\title{
Mitochondrial effects of 3 years of CD4-guided HIV treatment interruption
}

\author{
G Garrabou*1, E Negredo², C Morén ${ }^{1}$, J Romeu ${ }^{2}$, B Rodríguez-Santiago ${ }^{3}$, \\ M Nicolàs ${ }^{1}$, Ò Miró ${ }^{1}$, F Cardellach ${ }^{1}$, J Puig' ${ }^{2}$, N Pérez-Álvarez², R López- \\ Blánquez $^{2}$, L Ruiz ${ }^{4}$, R Bellido ${ }^{4}$, C Miranda ${ }^{2}$ and B Clotet ${ }^{5}$
}

Address: ${ }^{1}$ Mitochondrial Research Laboratory-IDIBAPS-University of Barcelona-Hospital Clinic of Barcelona and CIBER de Enfermedades Raras, Barcelona, Spain, ${ }^{2}$ Lluita contra la SIDA Foundation-Hospital Germans Trias i Pujol-Universitat Autonoma of Barcelona, Badalona, Spain, ${ }^{3}$ Gentics Unit-Department of Experimental and Health Sciences-Universitat Pompeu Fabra, Barcelona, Spain, ${ }^{4}$ Irsicaixa Foundation-Hospital Germans Trias i Pujol-Universitat Autonoma of Barcelona, Badalona, Spain and ${ }^{5}$ Lluita contra la SIDA and Irsicaixa Foundations-Hospital Germans Trias i PujolUniversitat Autonoma of Barcelona, Badalona, Spain

* Corresponding author

from Ninth International Congress on Drug Therapy in HIV Infection

Glasgow, UK. 9-13 November 2008

Published: 10 November 2008

Journal of the International AIDS Society 2008, I I (SuppI I):PI42 doi:I0.II86/I758-2652-I I-SI-PI42

This abstract is available from: http://www.jiasociety.org/content/I I/SI/PI42

(c) 2008 Garrabou et al; licensee BioMed Central Ltd.

\section{Purpose of the study}

Mitochondrial toxicity of antiretroviral treatment (ARVT), especially nucleoside-analogues' capacity to inhibit DNApolymerase gamma, has been proposed as the ethiopathological mechanism which underlies many of the secondary effects of HIV therapy. The aim of the present study was to evaluate whether a prolonged CD4 cellguided ARVT interruption could reverse mitochondrial toxicity.

\section{Methods}

We included 38 patients from the TIBET study whose peripheral blood mononuclear cells (PBMCs) had been collected at baseline, at 96 and at 144 weeks throughout the study period; 18 of them discontinued ARVT along this time and 20 maintained therapy. Mitochondrial DNA (mtDNA) content was measured by real-time PCR and mitochondrial function through the spectrophotometric measurement of cytochrome C oxidase (COX) enzymatic activity normalised by mitochondrial content using citrate synthase (CS) activity (COX/CS ratio).

\section{Summary of results}

Whereas mtDNA content showed a similar progressive decrease throughout the study period in both study arms, only for the control group was this significant either at week $96(15 \%$ decrease, $\mathrm{p}=0.03)$ or at week $144(34 \%$ decrease, $\mathrm{p}=0.01)$. The COX/CS ratio significantly improved in patients who interrupted antiretroviral therapy in comparison with those who did not, especially at week $96(130 \%$ increase, $\mathrm{p}=0.06)$. The univariate and multivariate analysis performed showed that only CD4+ T-cell value at the time of ARVT initiation and time with viral suppression before the study were associated with changes in the COX/CS ratio.

\section{Conclusion}

PBMCs' mitochondrial function improved during a prolonged ARVT interruption in spite of mtDNA content decrease. The absence of correlation between mitochondrial parameters suggests the existence of a mitochondrial transcriptional or translational upregulation mechanism which could be increasing mitochondrial protein expression in the absence of mtDNA content improvement, or also could be the reversion of an ARV-mediated mitochondrial toxicity mechanism that was previously disturbing mitochondrial function through a DNA polymerase gamma-independent way. 


\section{Acknowledgements}

This study was supported by: Fundació la Marató de TV3 020210 and 02063I, FIPSE 366I2/06, FIS 4038I/04 and 4I239/04, Suports a Grups de

Recerca de la Generalitat de Catalunya 2005/SGR/0300 and CIBER de

Enfermedades Raras (initiative of the ISCIII).

Publish with Bio Med Central and every scientist can read your work free of charge

"BioMed Central will be the most significant development for disseminating the results of biomedical research in our lifetime. " Sir Paul Nurse, Cancer Research UK

Your research papers will be:

- available free of charge to the entire biomedical community

- peer reviewed and published immediately upon acceptance

- cited in PubMed and archived on PubMed Central

- yours - you keep the copyright

Submit your manuscript here:

http://www.biomedcentral.com/info/publishing_adv.asp 